\title{
Multiple silent atherosclerotic aneurysms with penetrating ulcer of the aortic arch treated with a hybrid procedure
}

\section{Francesco Sbrana, Michele Coceani, Angelo Monteleone, Francesca Pignatelli, Christina Petersen, Dante Chiappino, Emilio M. Pasanisi, Sergio Berti}

Fondazione Toscana Gabriele Monasterio, Pisa, Italy

\section{ARTICLE INFO}

\section{Article history:}

Received: 3. 7. 2015

Received in revised form: 13. 10. 2015

Accepted: 14. 10. 2015

Available online: 10.11. 2015

Klíčová slova:

Aneurysma aortálního oblouku

Endovaskulární léčba

Hybridní léčba

Keywords:

Aortic arch aneurysm

Endovascular treatment

Hybrid treatment

\section{SOUHRN}

Aneurysmata aorty jsou výsledkem degenerativních procesů a abnormální tvorby elastinu a kolagenu. Kromě farmakoterapie zahrnuje léčba těchto aneurysmat jejich pravidelné sledování pomocí zobrazovacích metod, aby se vystihl ideální okamžik pro jejich chirurgické odstranění. Dnes je alternativním postupem hybridní léčba, kdy po debranchingu výkonu následuje implantace endograftu. Popisujeme př́pad pacienta s vícečetnými aneurysmaty aterosklerotické etiologie a s penetrujícím vředem aorty, jenž byl léčen hybridním prístupem.

(C) 2015 Published by Elsevier Sp. z o.o. on behalf of the Czech Society of Cardiology.

\section{ABSTRACT}

Aortic aneurysms result from degeneration and abnormal production of elastin and collagen. Besides medical therapy, management includes periodical imaging to identify the best moment for surgery. Nowadays, the alternative to traditional surgical techniques is represented by a hybrid approach in which debranching is followed by positioning of an endograft. We describe a case of a patient with multiple atherosclerotic aneurysms and a penetrating ulcer of the aortic arch treated with a hybrid approach.

\section{Introduction}

Aortic aneurysms result from degeneration or abnormal production of elastin and collagen. Atherosclerosis is the main pathological condition associated with degenerative aortic aneurysms and several mechanisms - inflammation, proteolysis, biomechanical wall stress - contribute to the degenerative process. Thoracic aneurysms may involve one or more segment and the etiology, natural history and treatment may vary [1]. An alternative phenotype of aortic aneurysms is the penetrating ulcers which, in $40 \%$ of cases, may lead to complications such as dissection, intraparietal hematoma, rupture and perforation [2].
The management of aortic aneurysms includes medical treatment, which aims to slow their growth and thereby reduce the risk of dissection and rupture, and surgery. It is also fundamental to carry out periodical imaging studies in order to identify the best possible moment for surgery.

Nowadays, because traditional surgical techniques are burdened by high mortality and morbidity especially in surgery of the aortic arch $[3,4]$, hybrid procedures have been proposed that involve arch debranching followed by stenting of the aortic arch [5].

In this report, we describe a case of a patient with multiple silent atherosclerotic aneurysms with a penetrating ulcer of the aortic arch treated with a hybrid procedure. 


\section{Case report}

A 74-year-old man was admitted to our Institute for heart failure. At admission he presented NYHA class III dyspnea and peripheral edema. The patient had previously undergone percutaneous coronary intervention and coronary artery bypass surgery, as well as implantation of a pacemaker. He was also affected by diabetes mellitus and chronic kidney disease (creatinine $2.5 \mathrm{mg} / \mathrm{dl}$, estimated Glomerular Filtration Rate - eGRF $23 \mathrm{ml} / \mathrm{min} / 1.73 \mathrm{~m}^{2}$ ). Due to severe left ventricular systolic dysfunction (ejection fraction $27 \%$ ), the patient was scheduled for upgrading to a biventricular pacemaker.

The chest X-ray, performed before the electrophysiological procedure, showed a broadened mediastinal shadow with a double contour of the upper left arch in the postero-anterior projection and a pseudo-nodular area projected on the upper margin of the posterior aortic arch in the latero-lateral projection (Fig. 1).

In relation to these findings, which were compatible with a pathology of the aortic arch, computer tomography was performed which showed multiple aortic arch aneurysms associated with an ulcerative lesion localized on zones 1, 2 and 3 (according to the Criado/Ishimaru classification [6] - Fig. 2).

To prevent contrast-induced nephropathy, a fluid volume load of sodium bicarbonate and normal saline was administered [7]. Despite the high risk of contrast-induced acute kidney injury [7], no such event was reported in this patient.

A hybrid procedure involving arch debranching followed by stenting of the aortic arch was considered given the multiple atherosclerotic aneurysms and a penetrating ulcer of the aortic arch, and in view of the major comorbidities. Due to involvement of the aortic arch between the innominate and left common carotid artery (zone 1 of the Criado/Ishimaru classification [6]) the patient was first scheduled for combined carotid-carotid and carotid-subclavian bypass (Dacron prosthesis $-\varnothing 8$ $\mathrm{mm}$ ) in order to create an adequate landing zone for the endograft.

After 3 weeks, control angiography was performed which showed correct function of the graft. Subsequent$\mathrm{ly}$, the patient underwent positioning of two endografts (Bolton Relay ${ }^{\circledR} 28-30-34 \times 150 \mathrm{~mm}$ and Bolton Relay ${ }^{\circledR}$ 28 - 30-28 × 150 mm, Bolton Medical - Barcelona, Spain). The first endograft was placed immediately after the origin of the innominate artery and the second one was partly overlapped to the previous one to isolate the whole area involved by the penetrating ulcer. In this manner, isolation of multiple atherosclerotic aneurysms, as well as of the penetrating ulceration, was obtained. The procedure, carried out in local anesthesia and with percutaneous approach, was performed without any complications and at 18 month follow-up the patient was stable.

\section{Discussion}

We describe a case of multiple atherosclerotic aneurysms with a penetrating ulcer of the aortic arch in a subject with major comorbidities (post-ischemic heart failure, diabetes mellitus, and chronic kidney disease).

The presence of a penetrating ulcer is an indication for surgery, along with symptomatic aneurysms with a diameter greater than $6 \mathrm{~cm}$, growth greater than $1 \mathrm{~cm}$ per year and concomitant Marfan syndrome [1]. All of these conditions have a high risk of rupture. The comorbidities of the patient could have further compromised traditional surgical techniques, already burdened by high mortality and morbidity, especially for surgery of the aortic arch [3]. Nowadays, the hybrid approach, in which a debranching procedure precedes an endograft deployment, is a valid approach in the case of an aortic aneurysm caused by the progression of the atherosclerotic process in subjects which have previously undergone conventional open repair [8] of the descending aorta. A meta-analysis has confirmed the validity of this technique which provides
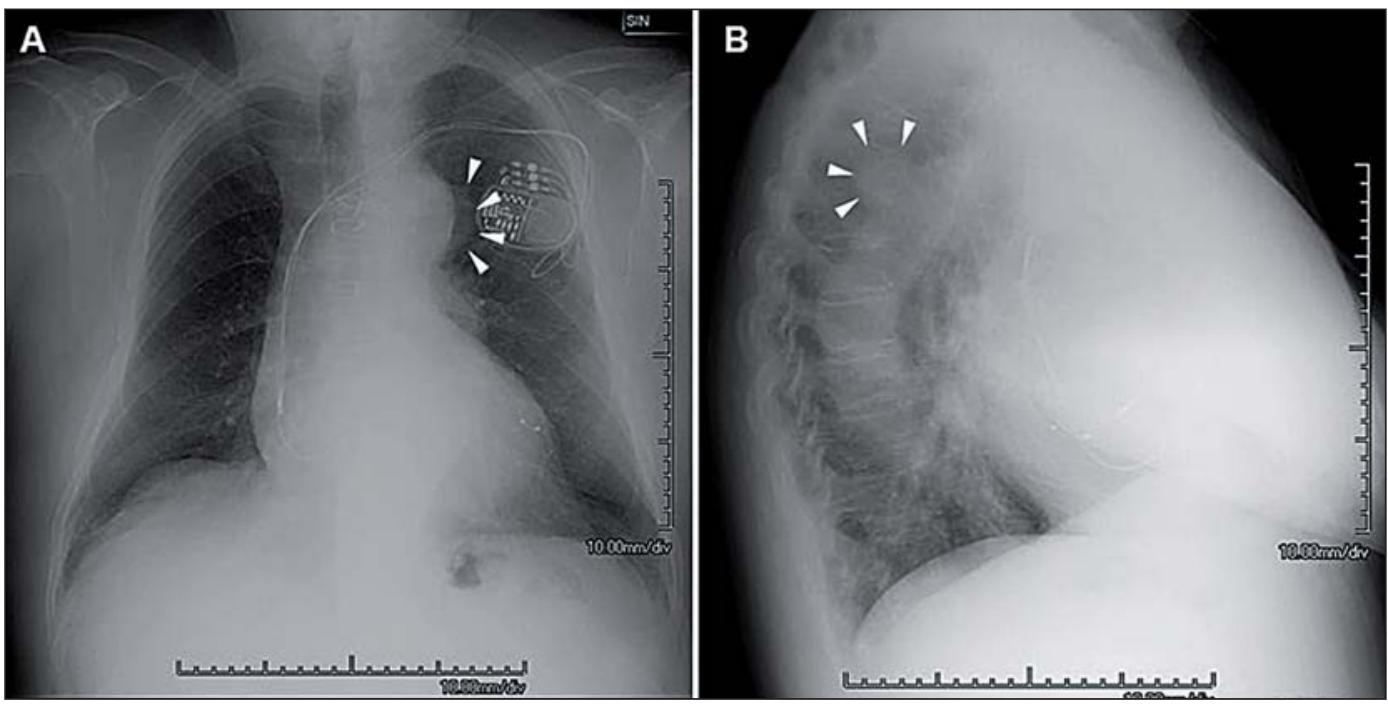

Fig. 1 - Chest X-ray. Panel A - widening of the mediastinal shadow with double contour of the first left arch (arrows) in the postero-anterior projection. Panel B - pseudo-nodular area projected on the upper margin of the posterior aortic arch (arrows) in the latero-lateral projection. 

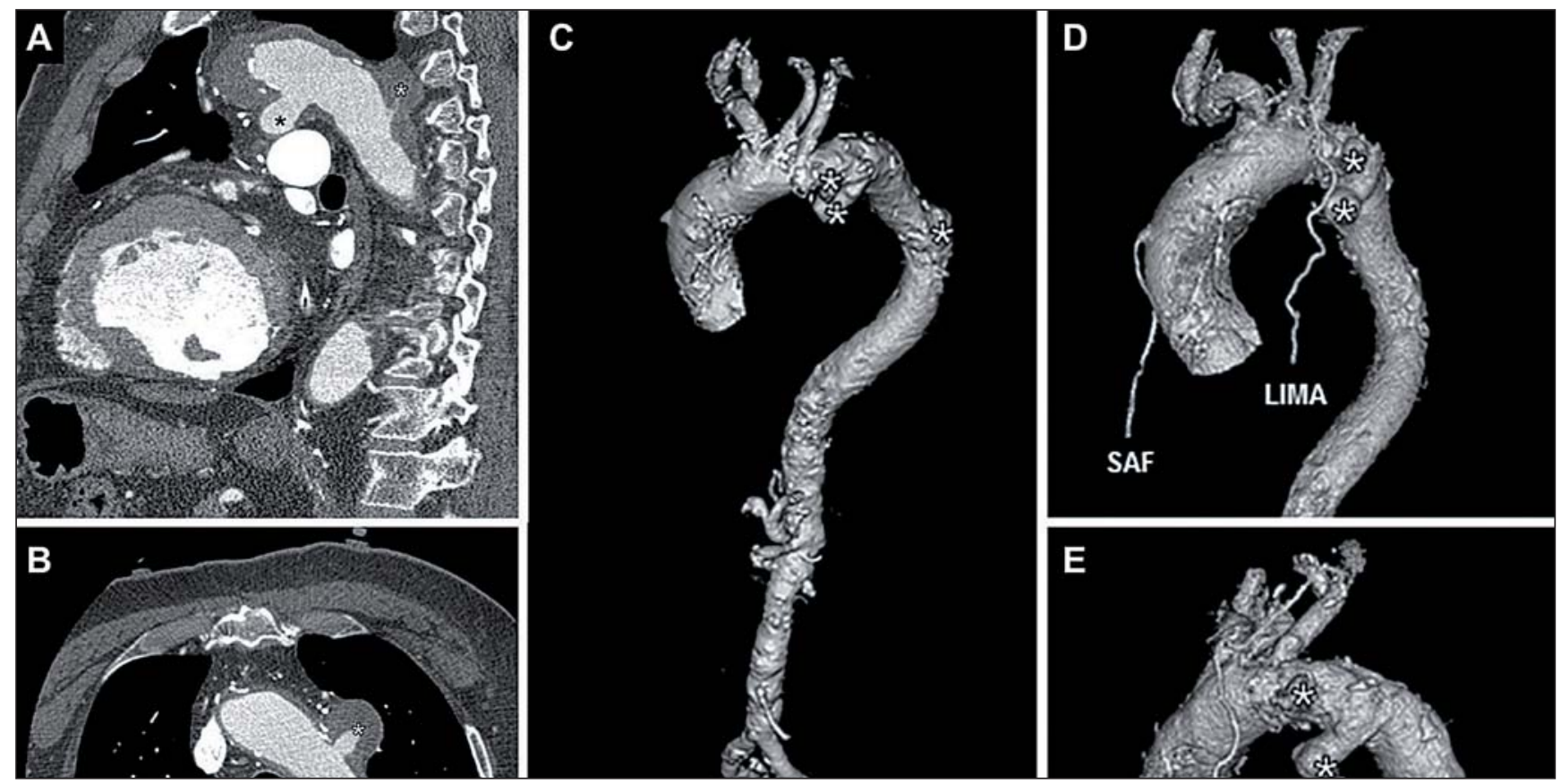

Fig. 2 - Computed tomography. Panel A - para-sagittal reconstruction showing an aneurysm on the ventral wall (black asterisk) and an aneurysm on the superior wall of the aortic arch (white asterisk). Panel B - transverse reconstruction showing an aneurysm on the lateral wall (white asterisk) and an aneurysm on the posterior wall of the aortic arch (white circle). 3D view of angiography computed tomography of multiple aortic arch aneurysm showing the relationship of the aneurysms with epiaortic vessels and with coronary artery bypass grafts. Panel C - thoraco-abdominal aorta volume rendering. Panels D and E - thoracic aorta volume rendering. White asterisks indicate the aneurysms. LIMA - left internal mammary artery; SAF - saphenous vein graft.

a safe alternative to open repair with acceptable shortand mid-term results, although stroke and mortality rates remain non negligible [5]. Our patient at 18 months follow-up was stable confirming that thoracic endovascular aortic repair had a good long-term result. Indeed, Desai et al. reported with this technique a freedom from reintervention on the treated segment of $85 \%$ at 10 years [9]. In recent years, endovascular debranching with chimney stents is emerging as an alternative. This technique provides a minimally invasive alternative which dramatically reduces the aggressiveness of the procedure in the arch, but more long-term data are needed to define the safety of this approach [10].

The radiologist plays a key role in this pathology because frequently, as in our case, the patient is asymptomatic. However, following a standard chest $\mathrm{X}$-ray, pathognomonic radiological signs highlighted the widening of the mediastinal shadow with a double contour of the first left arch and a pseudo-nodular area projected on the upper margin of the posterior aortic arch. Moreover, radiologists also perform periodic imaging studies so as to decide the optimal surgical timing [1]. Imaging is also important to identify the correct proximal landing zone, which determines the surgical approach, as well as to document the integrity of the supra-aortic vessels and intracranial circulation $[11,12]$.

A further peculiarity of our case is the concomitant chronic kidney disease (creatinine $2.5 \mathrm{mg} / \mathrm{dl}$ - eGFR $23 \mathrm{ml} /$ $\min / 1.73 \mathrm{~m}^{2}$ ) and the need to administer iodinated contrast both for diagnostic purposes as well as during the procedure of endograft positioning. The risks of acute kidney injury following contrast medium administration in this patient were also high due to concomitant diabetes mellitus and congestive heart failure. However, because the patient was adequately hydrated [13], contrast medium use was limited (also avoiding high osmolar agents), and nephrotoxic medications were discontinued [7], it was possible to avoid contrast induced nephropathy.

\section{Conclusions}

In conclusion, hybrid procedures are a safe and effective therapy for patients with multiple thoracic aortic aneurysms, especially in subjects with significant comorbidities.

\section{Conflict of interest}

No conflict of interest.

\section{Funding body}

None.

\section{Ethical statement}

I declare, on behalf of all authors, that the research was conducted according to Declaration of Helsinki.

\section{Informed consent}

I declare, on behalf of all authors, that informed consent was obtained from all patients participating in this study.

\section{References}

[1] E.M. Isselbacher, Thoracic and abdominal aortic aneurysms, Circulation 111 (2005) 816-828.

[2] H. Hayashi, Y. Matsuoka, I. Sakamoto, et al., Penetrating atherosclerotic ulcer of the aorta: imaging features and disease concept, Radiographics 20 (2000) 995-1005. 
[3] J. Bachet, B. Goudot, G. Dreyfus, et al., How do we protect the brain? Antegrade selective cerebral perfusion with cold blood during aortic arch surgery, Journal of Cardiac Surgery 12 (1997) 193-200.

[4] J.S. Coselli, S.Y. Green, Aortic arch repair today: open repair is best for most arch lesions, Journal of Cardiovascular Surgery (Torino) 56 (2015) 531-546.

[5] K.G. Moulakakis, S.N. Mylonas, F. Markatis, et al., A systematic review and meta-analysis of hybrid aortic arch replacement, Annals of Cardiothoracic Surgery 2 (2013) 247-260.

[6] R.S. Mitchell, S. Ishimaru, M.P. Ehrlich, et al., First International Summit on Thoracic Aortic Endografting: roundtable on thoracic aortic dissection as an indication for endografting, Journal of Endovascular Therapy 9 (2002) II98-II105.

[7] R.J. Owen, S. Hiremath, A. Myers, et al., Canadian association of radiologists consensus guidelines for the prevention of contrast-induced nephropathy: update 2012, Canadian Association of Radiologists Journal 65 (2014) 96-105.

[8] Y. Matsuno, K. Shimabukuro, N. Ishida, et al., Staged hybrid debranching and thoracic endovascular aneurysm repair for multiple aortic aneurysms after conventional open repair of the descending aorta: a case report, Annals of Vascular Diseases 5 (2012) 225-228.

[9] N.D. Desai, K. Burtch, W. Moser, et al., Long-term comparison of thoracic endovascular aortic repair (TEVAR) to open surgery for the treatment of thoracic aortic aneurysms, Journal of Thoracic and Cardiovascular Surgery 144 (2012) 604-609.

[10] N. Mangialardi, S. Ronchey, A. Malaj, et al., Value and limitations of chimney grafts to treat arch lesions, Journal of Cardiovascular Surgery (Torino) 56 (2015) 503-511.

[11] D. Laganà, G. Carrafiello, D. Lumia, et al., Hybrid treatment of isolated aortic arch aneurysms, La Radiologia Medica 114 (2009) 1130-1140.

[12] H. Rousseau, V. Chabbert, M.A. Maracher, et al., The importance of imaging assessment before endovascular repair of thoracic aorta, European Journal of Vascular and Endovascular Surgery 38 (2009) 408-421.

[13] P. Calabrò, R. Bianchi, M. Caprile, et al., Use of $\mathrm{NaCl}$ saline hydration and N-Acetyl Cysteine to prevent contrast induced nephropathy in different populations of patients at high and low risk undergoing coronary artery angiography, Minerva Cardioangiologica 58 (2010) 35-40. 